\title{
Consensual and Entrepreneurial Culture: Insights from Organisational Culture and Human Resource Development Policy in Nigerian Banks
}

\author{
Sulaiman Olusegun Atiku
}

School of Management, Information Technology and Governance, University of KwaZulu-Natal, Golf Road, Pietermaritzburg, South Africa,

Email: atiku@ukzn.ac.za

\section{Prof Pepukayi Chitakunye}

School of Economic and Business Sciences, University of the Witwatersrand, Johannesburg, South Africa Email: pepukayi.chitakunye@wits.ac.za

\section{Dr Ziska Fields}

School of Management, Information Technology and Governance, University of KwaZulu-Natal, University Road, Westville, South Africa, Email: fields@ukzn.ac.za

\section{Doi:10.5901/mjss.2014.v5n20p101}

\section{Abstract}

This study contributes to an understanding of consensual and entrepreneurial culture in organisations within the context of communicating organisational culture through human resource policy. Given that consensual and entrepreneurial culture has the potential to shape employee attitudes and work behaviours towards the attainment of business efficiency and sustainability, this study examined the relationship between organisational culture and Human Resource (HR) development policy. Two hypotheses were formulated and tested to establish the significance of the relationship between organisational culture and HR development policy. We adopted a quantitative approach, utilising a structured questionnaire $(n=305)$ and other documented evidence. The study used a combination of convenience sampling and simple random sampling techniques to select the respondents. The findings revealed that there is a significant relationship between organisational culture and HR development policy. It was found that consensual culture as a dimension of organisational culture has the greatest influence on HR development policy, and consequently the entrepreneurial mentality and creativity within the organisation. We conclude that there is a strong positive relationship between organisational culture and HR development policy as an antecedent of $H R /$ organisational outcome in the Nigerian banking sector. This paper recommends that consensual and entrepreneurial cultures are crucial for business sustainability in the knowledge-based global economy.

Keywords: consensual values, entrepreneurial values, learning and development policy, organisational culture, sustainable competitive advantage.

\section{Introduction}

The dynamic nature of business activities in the present day global economy requires adaptive culture and human resource development policy for sustainability (Naranjo-Valencia et al., 2011; Thite 2011). This is a kind of economy that revolves around knowledge creation and innovation as a coping strategy towards sustainable competitive advantage (Thite, 2011). While one of the factors responsible for the attainment of business sustainability is organisational culture through its innovative orientation (Naranjo-Valencia, Jiménez-Jiménez, \& Sanz-Valle, 2011), there is a dearth of research that focuses on the link between organisational and human resource development policy across the globe (Metcalfe, 2011). The link between organizational culture and performance on the other hand has attracted attention from many scholars (Cheung et al., 2012; Deshpande \& Farley, 1999; Ezirim et al., 2010; Gambi et al., 2013; Gregory et al., 2009; Prajogo, et al., 2012). Within this context, there are few studies that offer explanations about the link between organisational culture and performance (Hartnell, Ou, \& Kinicki, 2011; Prajogo \& McDermott, 2011). This paper begins the first stage of the explanatory analysis on the link by adopting human resource development policy as an antecedent of human resource/organisational outcomes or sustainable competitive advantage. The global economy is characterised 
with high levels of creativity and innovations necessitating suitable cultural dimensions as well as learning/development policy in line with the variations. Whilst previous research has focused more on understanding the link between organisational culture and performance in more developed economies across Europe and America, there are limited insights on this issue from an African context. To explore the nexus between organisational culture and corporate performance, this study draw insights from the Nigerian banking sector.

The overall objective of this paper is to contribute to an understanding of the importance of consensual and entrepreneurial cultures in organisations. We achieve this by drawing insights from the exploration of the relationship between organisational culture and human resource development policy within the commercial banks in Nigeria. The study was guided by the following objectives:

- To determine the relationship between the dimensions of organisational culture and HR development policy;

- To identify the cultural dimension that has the highest level of significance on human resource development policy.

Drawing from the literature and the study objectives, it was hypothesised that:

$\mathrm{H} 1$. There is a relationship between organisational culture and human resource development policy.

$\mathrm{H} 2$. There is a significant relationship between the cultural dimensions and HR development policy as an antecedent of human resource/organisational outcomes.

\section{Literature Review}

\subsection{Organisational culture}

Ezirim, Nwibere, and Emecheta (2010b) described organisational culture as the mind-set, experience, philosophies and norms of an organisation. This is a set of standards and disciplines that shapes the conduct of individual employee and teams in an organisation, as well as other stakeholders. It is our contention that Ezirim et al. (2010b) definition of organisational culture is silent on the variations but perceived corporate culture as the mind-set, norms, philosophies and standards of the organisation in order to guide and nurture members attitudes and behaviours. Consciousness of the variations in the external business environment is key towards the attainment of sustainability in the global economy. This is the uniqueness of Kotter and Heskett (1992) adaptive culture, which is flexible enough to accommodate the variations in the business environment; in term of responsiveness to changes in customers' taste, technological innovations and competitors' strategies to put the competing firms out of the market.

Organisational culture encompasses 'the implicit values, beliefs, and assumptions that employees infer guide behavior, and they base these inferences on the stories, myths, and socialisation experiences they have and the behaviours they observe (especially on the part of leaders) that prove to be useful and promote success'(Schneider, Ehrhart, \& Macey, 2013). Within this context, there is need to communicate organisational culture through human resource policy to present the values, philosophies and assumptions in an explicit form in order to adequately shape employee attitudes and work behaviours.

In this study, we take the view that organisational culture relates to shared norms, beliefs, as well as principles that shape employees' attitude and behaviour towards the realisation of operational outcomes. This serves as a guideline to nurturing and shaping employee attitudes and behaviour through human resource development policy in order to accomplish organisational goal and objectives (organisational performance). Further, it is our contention that the variations in the business environments could be addressed through human resource development policies.

\subsection{Organisational culture and performance}

There are different conceptual clarifications on organisational culture, as well as different cultural dimensions that emerge in from the literature. For instance, competing values framework as a four dimensional measurement of organizational culture was developed by Robert, Quinn and Kimberly in the 1980s was classified based on the frame work of clan, adhocracy, hierarchy and market (Hartnell et al., 2011). Hofstede and GLOBE argument on the dimensions of organizational culture was derived from the dimensions of national culture, which include; power distance, uncertainty avoidance, individualism / collectivism and masculinity / femininity (Javidan, House, Dorfman, Hanges, \& Luque, 2006). Deshpande and Farley (1999) on the other hand, assessed the cultural values of work organisations in Asia using bureaucratic, competitive, consensual and entrepreneurial values system. Denison's model cultural values in work organisations was based on four core values namely; involvement, consistency, adaptability and mission(Denison, Haaland, \& Goelzer, 2004). Recently, Mathew, Ogbonna, and Harris (2012) measured organizational culture based on 
company's mission, employee concerns and trust, learning and development practices, members empowerment and other core principles.

Drawing from these different concepts, we consider the Deshpande and Farley's cultural dimensions most appropriate for this study. Deshpande and Farley's types of organisational culture were found useful in the $21^{\text {st }}$ century management practices or global economy that is characterised with vast technological innovations, sustainable competitive advantage and total customers satisfaction. This is in relation to their entrepreneurial, competitive and consensual cultures respectively. Unfortunately, the major short coming of their study is that insights were drawn from only two countries. As such, this limits the generalizability of their findings to the entire global community. However, there are some theoretical generalizations that can be made.

Ezirim et al. (2010b) on the other hand, studied the relationship between organisational culture and performance in Nigeria using Deshpande and Farley's cultural types to measure performance of Oil companies in the southern part of Nigeria. The study examined seven (7) major Oil companies in the region and copies of three hundred and fifty (350) questionnaires were distributed to managerial employees among the companies examined. The data collected were analysed using spearman rank correlation coefficient and multiple regression analysis. The findings revealed that competitive, entrepreneurial and consensual cultures were positive and significantly influencing organisational performance. Although, the result is similar to that of Deshpande and Farley (1999), there is limited generalisability since Oil companies around the world are known for outstanding performance because of the demands and prices of crude Oil in the world market. Further, the study focused on a single region of Nigeria and drew insights from seven companies to predict the relationship between organisational culture and performance in Nigeria. Considering the fact that the Oil and Gas sector is just a sector of the huge Nigerian economy, making generalisation or prediction based on the data collected from the sector for the entire economy may not be appropriate. However, theoretical generalisations can be made from the insights that emerged from their findings.

Similarly, Ezirim, Nwibere, and Emecheta (2012) are of the view that shared norms and values system in a business organisation has a major impact on employee's level of loyalty to the organisation as reflected in the psychological contract between the organisation and individual employee. The study proposed that proper management of shared norms and values system in the form of internal control mechanisms will lead to employee loyalty. Members' loyalty is seen as a strong indicator of outstanding organisational outcomes. The shortcoming of this position is that, the scholars used the same set of data collected in 2010 from the major Oil companies in Nigeria for the study of the relationship between organisational culture and performance to also predict the impact of culture on employee's loyalty. This has its own limitations because of the level of variations in the external business environment which often times affect the internal control mechanism. The variations most often, caused changes in shared norms and values system within the organisation. Given the rapid technological advances and changes, two years is too long considering the level of changes in technology, client taste and demands in the knowledge-based global economy.

Ojo (2010) examined the relationship between corporate culture and performance using all commercial banks in Nigeria as study. The commercial banks were divided into two strata: comprising 'old' and 'new' generation banks, two banks were randomly drawn from each stratum. Eighty (80) respondents were randomly drawn as sample size from the selected banks in the following categories; senior staff, directors and managers. The data collected were analysed using correlation and t-test via SPSS. The study revealed that organisational culture and banks effectiveness are positively correlated. However, there was a lack of clarity on the cultural dimensions used in measuring organisational culture, inadequacy of data and methodological triangulation. Another shortcoming of the study was limited use of inferential statistical analysis to explain 'how' and 'why' corporate culture influences bank effectiveness in Nigeria. This is a major concern of this study.

The foregoing suggests the need not only to investigate the relationship between organisational culture and human resource development policy as an antecedent of organisational performance, but also to offer the first stage of explanation on the link between culture and performance focusing on the banking sector. The current study is located at this intersection, and adopts Deshpande and Farley's cultural dimensions in order to investigate the link between organisational culture and human resource development policy in the Nigerian banking sector. Deshpande and Farley's cultural dimensions as a measurement in the study were adopted to explore the interplay between culture and human resource development policy in the Nigerian baking sector, because of its ability to assess items of quality and innovation outcomes concurrently (Prajogo \& McDermott, 2011). The relevance of these cultural dimensions on operational efficiency in the banking sector and knowledge-based global economy cannot be underestimated. As in Madu (2011), the competitive culture can be used as a yardstick to overcome the challenges of sustainable competitive advantage in the global economy. The entrepreneurship culture as an antecedent of entrepreneurial orientation to stimulate innovativeness and pro-activeness among members of the organisation (Engelen, 2010). Entrepreneurial 
orientations may also have great influence on operational efficiency in the banking sector, while entrepreneurship culture could be used as a measure to overcome the challenges of vast technological innovations as characterised in the global economy. Consensual culture on the other hand, could be used as a measure to shape or nurture employee attitude and behaviour towards the realisation of total customer's satisfaction, which is also key to sustainability in the global economy.

Recent studies on the interplay between culture and firms' performance led to the realisation of the need to create mediating variable(s), in order to explain the link between culture and operational efficiency (Cheung, Wong, \& Lam, 2012; Gregory, Harris, Armenakis, \& Shook, 2009; Hartnell et al., 2011; Prajogo, Chowdhury, Yeung, \& Cheng, 2012; Prajogo \& McDermott, 2011). From the literature discussed in this section, we now know that there has been limited attempt to provide detailed explanations on the association between organisational culture and firms' financial outcomes. It may not be sufficient to state the degree of the relationship or indicate that positive or negative relationship exist between the two constructs. Agreeing with (Hartnell et al., 2011; Prajogo \& McDermott, 2011), what is needed is an approach that utilises mediating variable(s) to provide a comprehensive explanation on the link between culture and performance of the organisation. Our study is located at this juncture.

Gambi, Gerolamo, and Carpinetti (2013) examined the link between organisational culture and performance of the organisation through quality management procedures. Their study was based on the assumption that cultural dimensions utilised in corporate organisation will play a significant influence on the outcomes of such organisation. Similarly, Prajogo and McDermott (2011) examined the association between corporate culture and operational outcomes of firms by drawing emphasis from adaptive perspectives. Here, they used operational outcome as a major antecedent of corporate financial outcomes. From their findings, we learn that operational outcomes or efficiency could be used as a mediating variable in the association between organisational culture and firms economic outcomes. One shortcoming of Prajogo and McDermott's study is based on the failure to create organisational performance as an endogenous variable. Further, using operational outcomes as mediating variable in the proposed model was a great concern in the choice of structural equation modelling. The scholars concluded that operational efficiency will influence corporate economic outcomes, but we are of the view that their statistical evidence could have been much deeper. To overcome some of the limitations in previous studies, and close the gaps identified in the literature, our study therefore, adopted Human Resource (HR) development policy as an antecedent of operational efficiency.

\subsection{Communicating organisational culture through human resource development Policy}

Human resource development policy is more concerned with the standards, principles and philosophies guiding the development of potential human resources in order to shape employees attitude and work behaviours which will ultimately impact on organisational outcomes (Thang, Quang, \& Buyens, 2010). This suggests that organisational culture and human resource policy share the same objective, which has to do with shaping employees' attitude and work behaviour towards the realisation of organisational goals and objectives. This warrants a further review of literature surrounding learning culture, organisational learning, learning and development programmes, as this will help to provide a deeper understanding of the phenomenon under investigation.

\subsubsection{Learning culture}

Werner and DeSimone (2009) described learning as a critical aspect of the entire human resource development efforts. According to Werner and DeSimone, learning could be defined as a relatively permanent change in behaviour, cognition or affect that occurs as a result of one's interaction with the environment. On the other hand, Armstrong (2009) referred to learning culture as a type of culture that place greater emphasis on learning and considers acquisition of knowledge, skills and dynamic capabilities. These are widely shared and held by all members of an organization as absolutely necessary for essential organizational process. Members within this type of organisation are committed to continuous engagement in education as a critical factor influencing organisational outcomes.

In a similar vein, Debowski (2006) perceives learning culture as a knowledge culture through which an employee sees and takes knowledge dissemination as an acceptable behaviour within an organisation. Knowledge culture can be seen as way of ensuring sustainability in the knowledge-based global economy. A shared learning culture conveys the following principles as illustrated in the figure 1 below: 
Figure 1: Implicit values of shared learning culture

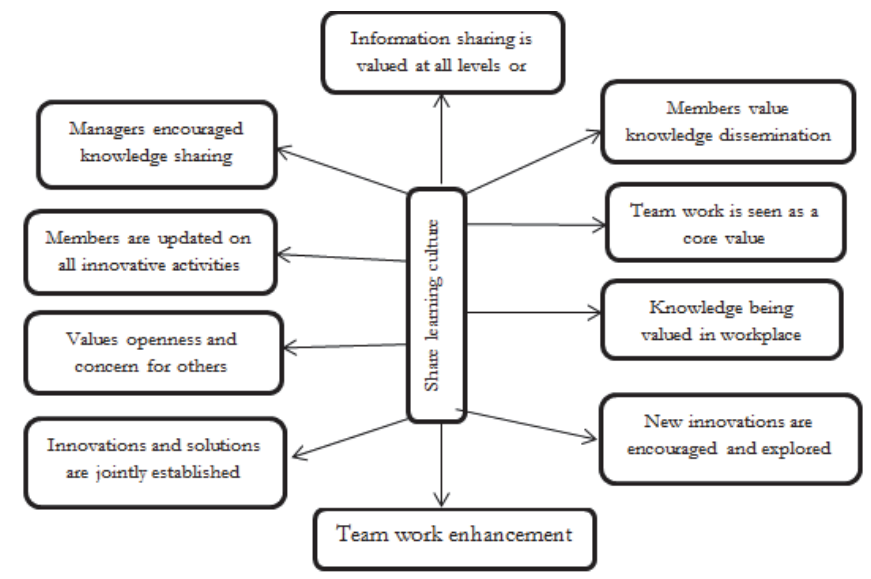

Source: Adapted from Debowski (2006, p. 85)

The principle illustrated in figure 1 revolves around what Debowski referred to as knowledge culture enablers. These enablers were classified into four categories: the first category focused on knowledge dissemination as a core value system within the organisation to achieve innovative capabilities among members. The second enabler or category (structural support), ensures that knowledge are communicated at various levels or units in the organisation. The third enabler is referred to as enacted values, this encourage participative management or joint consultation in decision making process and knowledge sharing procedures. The fourth enabler has to with the quality of interactions among members of the organisation; this is achieved through coaching, mentorship and team learning programmes. Examples of organisations where knowledge culture is being practiced include universities, colleges and other institutions of higher learning, as well as information technology based organisations. In these organisations, research is vital and outcomes of studies are adequately disseminated.

Reynolds (2004) describes a learning culture as a medium that encourages employees' commitment to a range of positive discretionary behaviours and learning. This suggests that development of organisational practices that will enhance employees' commitment and offers practical supports for knowledge creation are required to create a learning culture among employees. The following ways for developing a learning culture were suggested: vision must be developed and shared by all member of the organisation, create employees commitment, implement participative management style, provide a conducive learning environment for employees, adopt a mentoring techniques to duplicate talents, support employees with resources required to meet challenging tasks, encourage management staff to act as role model for employees to emulate, encourage teamwork, avoid bureaucratic structure as it creates problems rather than facilitate activities and align structures to vision.

\subsubsection{Organisational learning}

Slater and Narver (1995) in Škerlavaj, Štemberger, Škrinjar, and Dimovski (2007) referred to organisational learning as a complex process targeted to enhance innovative and creative thinking among employees in order to improve employees' attitude to work and work behaviour. Murray and Donegan (2003) put it that organisational learning is a procedure that has to do with development of potentials to shape employee and organisational behaviour. Dimovski (1994) submitted a review of literature on organizational learning and came up with four different perspectives on organisational learning; procedure of gathering facts, clarification of facts, modifying behaviour and intellectual modifications which will have a positive influence on success of the organisation. Armstrong (2009) on the other hand, suggests that learning organisation integrates concepts such as; human resource development, systematic training, action learning, organisational development and knowledge management. 


\subsubsection{Organisational Learning Culture}

The development of organisational learning culture from a strategic point of view starts from individual employees as well as teams or groups and then to the organisation as whole is entrenched in the organisation's hierarchical structure (Garvin, 1993; Goh, 1998; Watkins \& Marsick, 2003). Organisational learning culture represents a knowledge-based view (KBV) of the firm that recognizes knowledge as a major determinant of sustainable competitive advantage (Hung, Yang, Lien, McLean, \& Kuo, 2010). While, Wilkens, Menzel, and Pawlowsky (2004) maintain that organisational learning culture are both a resource and a dynamic capability of a firm, their empirical study provides a model that social-technical process of knowledge management and organisational learning culture will generate organisational dynamic capabilities and core competences. This study suggests that communicating culture through learning and development policy could serve as a strong antecedent to improve human resource outcomes (employee skills, employee attitude and employee behaviour).

\subsubsection{Consensual and entrepreneurial culture}

Consensual values focused on loyalty, tradition and internal control mechanisms of the organisation, while entrepreneurial vales focused on innovation and risk taking capabilities of an organisation (Deshpande \& Farley, 1999). This implies that consensual values are internally oriented values system, and entrepreneurial values are externally oriented values system toward the realisation of corporate goals and objectives. Deshpandé and Farley (2004) claimed that the external oriented values made more contributions to organisational performance than the internal oriented values across the countries investigated. Hence, this study seeks to investigate the implications of internal and external values on human resource development policies in the Nigerian banking sector.

Lumpkin \& Dess (1996) in Huang and Wang (2011) claimed that entrepreneurial orientation has been examined under numerous classifications through which innovativeness, pro-activeness, and risk-taking capabilities were the most prominent set of values. Innovativeness has to do with the ability of work organisation to invest in knowledge leading to creation of new products or services (Huang \& Wang, 2011). This showcases the involvement of human resource development policy in the enhancement of innovative capabilities of an organisation toward invention of new products or services. Pro-activeness suggests consciousness of business environments both internal and external for immediate reaction to the change. Risk taking on the other hand, refers to the ability to take good advantage of business opportunities, undermining the associated risk.

\subsection{Learning and development as an antecedent of organisational outcomes}

Mello (2011) maintains that learning and development is more concerned with the micro aspect of firm needs and responsiveness while, organisational development takes holistic approach or focused on macro aspect of firm needs and responsiveness to environmental variations to boast corporate performance. Hence, organisational development could be referred to as an initiative for the enhancement of a firm's overall effectiveness or efficiency through strategic interventions undertaken towards the realisation of sustainable competitive advantage (Mello, 2011).

Similarly, Latif (2012) suggests that learning and development is linked to improved organisational performance and also serves as a major factor in shaping employees' attitude to work and improve the level of expected work behaviour. The study came up with an integrated model of learning \& development effectiveness and submitted that employees' satisfaction with the training programme is a major determinant of improved organisational performance. Mondy (2010) describes learning and development as a continuous process aimed at improving employees' dynamic capabilities as well as organisational outcomes. The study proposed that a well-developed workforce will distribute their capabilities to ensure organisational effectiveness and efficiency. The effects of learning and development will include positive changes in employees' attitude to work and behaviour, employees' commitment, employees' fulfillment, low level of absenteeism and labour turnover, customers' satisfaction and retention(Nadarajah, Kadiresan, Kumar, Kamild, \& Yusoff, 2012).

Banabou (1996) also maintain that a well-designed learning and development programme could be linked to improved organisational performance as well as higher returns on investment in learning and development. Banabou suggests that higher organisational performance could be achieved through appropriate determination of learning and development needs prior to the training programme. Clarke (2004) suggests that when an organisation takes proper evaluation of learning and development (both formal and informal learning), then its impact on organisational performance becomes positive. Clarke sees a positive link between learning/development and organisational 
performance, when learning outcomes lead to improved employees attitude to work and outstanding work behaviour.

Stavrou, Charalambous, and Spiliotis (2007) found that learning and development practices were solidly associated with organisational performance and also useful in achieving sustainable competitive advantage. They explain further that investment in human capital development, discovery of new ideas and development of potentials to bring about technological innovations and high level of creativity among employees in an organisation is a major source of sustainable competitive advantage. This suggests why Singh, Motwanis, and Komar (2000) put it that the challenges of globalisation and the need to remain competitive in the global economy force many business organisations to place greater emphasis on learning and development in order to shape employees attitudes and behaviours towards the latest development and in turn ensures effective human resource utilisation. Aggarwal and Bhargava (2009) identified two implications of human resource development on organisational performance. The first implication suggests that human resource development form employee competence, improved attitudes to work and increase employees' commitment which will in turn reflect on business outcomes. The second implication sees human resource development practices as capable of enhancing organisational performance through fundamental and operational efficiency. Hence, they concluded that learning and development have an impact on the performance of business organisations and also serves as a control mechanism to ensure effective employees attitude and behaviour leading to organisational effectiveness.

Human resource development focus on enhancement of potentials, competence, skills and capabilities required to ensures outstanding service delivery in organisations (Garavan \& Morley, 2006). More recently, Liao, Chang, Hu, and Yueh (2012) conducted an empirical investigation on the relationship between culture and innovativeness/effectiveness of the banking and insurance industries in Taiwan. The findings revealed that learning and development at organisational level greatly mediates the relationship between culture and business effectiveness in the industry. This also reveals the importance of knowledge sharing capabilities among members on innovativeness and effectiveness of an organisation. To advance this line of thinking, Kehinde, Jegede, Akinlabi, and ce (2012) propose that management development and mentorship programme is critical towards the attainment of sustainable banks effectiveness in Nigerian. Within this context, it is suggested that competence base level of the leadership structures, should be seen as a great determinant of sustainable competitive advantage in the industry.

\section{Methodology}

\subsection{Sample and procedures}

The population of this study comprises of 5 top rated commercial banks in Lagos, Nigeria with 5,387 employees. Only two of the commercial banks agreed to participate in the study, based on the principles of convenience sampling, three hundred and eighty (380) copies of the questionnaires were distributed evenly between the participating banks. To reduce the shortcomings that are associated with convenient sampling and ensure efficiency, ten (10) branches were randomly selected from each of the participating banks using simple random sampling (Hedt \& Pagano, 2011). This enables even distribution of questionnaires between the two bank headquarters and their major branches in Lagos. Hence, 306 questionnaires were returned; only one of the questionnaires was not properly completed and was discarded. The remaining 305 questionnaires represent $80.3 \%$ response rate.

\subsection{Measures}

Different tried and tested measures were adapted, and these are discussed below.

\subsubsection{Organisational Culture Scale (OCS)}

Insights are drawn from the Organisational Culture Scale (OCS), which was developed by Deshpande and Farley (1999), consisting of sixteen items and four dimensional scales. The first dimension covers four items on competitive cultures. The second dimension was designed to elicit information suitable for measuring entrepreneurship culture on four key items. The third dimension in the measuring instrument covers issues relating to bureaucratic cultures, containing four items. The last dimension on OCS was designed to gather information leading to adequate measurement of consensual culture. The reliability test for organisational culture starts from .814 to .877 . While, Cronbach's alpha coefficient for the four dimensional scale were; $.814, .821, .877$ and .815 respectively. Reliability test for organisational performance starts from .828 to .849 . Cronbach's alpha for profitability was .849 , sales volume was .844 , and market share was .828 . We consider the OCS as a suitable measuring instrument for investigating the relationship between organisational culture 
and performance in the modern day dynamic business environment. The strength of OCS lies on the four cultural dimensions that are crucial for business sustainability in the knowledge-based global economy. Again the competitiveness among commercial banks in Nigeria makes the competitive cultural dimension suitable. Creativity and innovations on electronic banking applications also calls for entrepreneurship cultural dimension as an appropriate instrument. The series of banking reforms, regulations and supervisory role of the Apex bank in Nigeria, as well as the expected compliance from the commercial banks; suggests the appropriateness of bureaucratic culture in measuring the level of internal control mechanisms in meeting the demands of the Apex bank. It is of particular significance to adopt a strategic measure to ensure total customer satisfaction, as this makes the consensual culture suitable for measuring customer satisfaction in this type of service organisation. More significantly, the OCS scale has been used by many researchers, and was found to have a high reliability coefficient, which implied its suitability for this study (Ezirim, Nwibere, \& Emecheta, 2010a; Ezirim et al., 2012; Rashid, Sambasivan, \& Johari, 2003). Its applicability in Nigeria produced internal consistency and Cronbach's coefficient alpha, which was examined via SPSS and yielded 0.80 and above. This result is consistent with the results generated by (Ezirim et al., 2010a, 2012). Hence, this study adapted the OCS as a measure of organisational culture on a four point Likert's type rating scale starting from 1 (strongly disagree) to 4 (strongly agree) because; the study requires the measurement of categorical opinions on organisational culture. This implies that respondents cannot be neutral on issues relating to the culture of their work place. The Cronbach's alpha coefficient for the sixteen items of OCS was 0.886 while the dimensional alpha coefficients for competitive, entrepreneurship, bureaucratic and consensual cultures were $0.757,0.807,0.730$ and 0.725 respectively.

\subsubsection{Dimensions of Learning Organisation Questionnaire (DLOQ)}

Dimensions of Learning Organisation Questionnaire (DLOQ) developed by Watkins and Marsick (2003), made up of three dimensional scales with a total of sixteen items, designed on a 6-point Likert's type rating scale; ranging from 1 (strongly disagree) to 6 (strongly agree). The first dimension measures Organisational Learning Culture (OLC) at individual level, the Cronbach's alpha was 0.81 , the second dimension on the scale measures OLC at group/team level with an observed Cronbach's alpha of 0.80 , while the third dimension measures OLC at organisational level, and the Cronbach's alpha yielded 0.88. The overall Cronbach's alpha coefficient for DLOQ was 0.93 . We consider this measuring instrument as valuable in the quest of measuring how organisational culture were communicated through human resource development policy or learning and development policy via induction course, coaching, mentoring and management trainee scheme, as well as other job sited learning and development methods. When corporate culture is communicated through learning and development policy, this could be referred to as organisational learning culture; a situation whereby individuals and teams embrace learning as a critical factor for sustainability (Wang, Yang, \& McLean, 2007).

This measuring scale was employed based on its three set of dimensions that stands as a better chance of measuring learning culture at individual, team and organisational level. The result may be helpful in identifying and recommending the level at which organisational learning culture will greatly influence human resource outcomes as an antecedent of organisational performance. A strong justification for employing DLOQ in this current study came as a result of its high reliability and validity recorded in previous studies (Egan, Yang, \& Bartlett, 2004; Ellinger, Ellinger, Yang, \& Howton, 2002; Hung et al., 2010; Wang et al., 2007). These studies employed DLOQ to examine the interplay between organisational learning culture and business financial outcomes. In the investigation leading to the identification of the appropriate measure or dimension for the assessment of learning culture, Yang (2003) affirms that DLOQ is a useful instrument for assessing the link between learning culture within an organisation and other vital organisational outcomes indicators.

Recent studies conducted by Song, Chermack, and Kim (2013) gave insights on the application of DLOQ by researchers in different countries across Asia, America, Australia, and Europe. This also provided insights on how previous studies employed DLOQ in terms of as antecedent, mediator/moderator and outcomes. This paper employed DLOQ as an antecedent of human resource/ organisational performance. The reason is that we approached corporate culture from cognitive perspectives. Hence, DLOQ was employed in this study on a four (4) point Likert's-type rating scale because; the study requires the measurement of emphatic opinions on organisational learning culture. This suggests that respondents cannot be neutral or form a slight opinion on issues relating the culture of their work place or environment.

\subsection{Data analysis procedures}

Consistent with previous studies in this area, data were coded and analysed using inferential statistics, and supported by the use of the IBM Statistical Package for Social Science (SPSS) version 21. Statistical tests were then conducted to find 
answers for the key research question and test the major hypothesis formulated.

\section{Results and Discussions}

The discussion under this section was based on the results that emanated from the test of formulated hypotheses. This is required for meaningful contribution to knowledge on the interplay between organisational culture and human resource development policies in the Nigerian banking sector.

\subsection{Relationship between organisational culture and HR development policy}

To establish the type of relationship between organisational culture and human resource development policy, this study adopted organisational culture scale to measure organisational culture on four different dimensions while dimensions of learning organisation questionnaire was employed to measure human resource development policy of the organisation at three crucial levels. The correlation matrix among the dimensions of organisational culture and human resource development policy is presented in the table 1 . The Pearson's product moment correlation confidents among the dimensions of organisational culture and human resource development policy will provide answers to the research question and also ensures the realisation of research objectives.

Table 1: Descriptive statistics and correlations among the indicators of organisational culture and human resource development policy

\begin{tabular}{|c|c|c|c|c|c|c|c|c|}
\hline & Mean & Std. Deviation & 1 & 2 & 3 & 4 & 5 & 6 \\
\hline 1 Competitive culture & 13.3410 & 2.05879 & - & & & & & \\
\hline 2 Entrepreneurial culture & 13.3344 & 2.10879 & $.613^{* *}$ & - & r & & & \\
\hline 3 Bureaucratic culture & 12.9836 & 1.87690 & $.535^{\star *}$ & $.542^{* *}$ & - & & & \\
\hline 4 Consensual culture & 12.6885 & 2.03539 & $.465^{\star *}$ & $.557^{\star \star}$ & $.507^{\star *}$ & - & & \\
\hline 5 Individual learning & 14.8164 & 2.67156 & $.367^{* *}$ & $.493^{* *}$ & $.392^{* *}$ & $.652^{* *}$ & - & \\
\hline 6 Team learning & 15.0656 & 2.61240 & $.268^{* *}$ & $.409^{* *}$ & $.388^{* *}$ & $.503^{* *}$ & $.688^{* *}$ & - \\
\hline 7 Organisational learning & 17.9541 & 3.15048 & $.242^{\star *}$ & $.360^{* *}$ & $.330^{\text {** }}$ & $.516^{\star *}$ & $.606^{\text {** }}$ & $.659^{* *}$ \\
\hline
\end{tabular}

${ }^{\star *}$ Correlation is significant at the 0.01 level (2 tailed).

Source: Field survey, 2014.

As evident in table 1, the results reveal that there are positive and significant relationships among the key indicators of organisational culture and human resource development policies in the Nigerian banking sector. The correlation coefficient ranges from $(r=.242-.688, p<0.01)$. With this result, it is suggested that there is a positive relationship between organisational culture and human resource policy. Table 1 explains the results of Pearson correlation between different types of organisational cultures observed in this study and human resource development policies at individual, team and organisational levels. Among the dimensions of organisational culture investigated in this study, entrepreneurial culture recorded the highest level of associations with the dimensions of human resource development policies in the Nigerian banking sector (see table 2). These results support Deshpandé and Farley (2004) claim that external oriented values (entrepreneurial culture) made more contributions to organisational performance. In this case, human resource development policy was used as an antecedent to organisational performance in the banking sector. This implies that learning and development at all levels in the Nigerian banking sector were positively associated with innovativeness, proactiveness and risk taking capabilities.

Table 2: Results of Pearson correlation among the dimensions of organisational culture and human resource development policy

\begin{tabular}{lccc}
\hline & Learning at Individual level & Learning at team level & Learning at organisational level \\
\hline Competitive culture & $.367^{* *}$ & $.268^{* *}$ & $.242^{* *}$ \\
Entrepreneurship culture & $.493^{*+}$ & $.409^{* *}$ & $.360^{* *}$ \\
Bureaucratic culture & $.392^{* *}$ & $.388^{* *}$ & $.330^{* *}$ \\
Consensual culture & $.652^{* *}$ & $.503^{* *}$ & $.516^{* *}$ \\
\hline
\end{tabular}

${ }^{* *}$ Correlation is significant at the 0.01 level (2 tailed).

Source: Field survey, 2014. 
Table 2 illustrates the relationship between competitive culture is positively correlated with the dimension of organisational learning at individual level $(r=0.367, p<0.01)$. This implies that competitive culture enhances individual level of desire for learning and development within the Nigerian banking sector. In relation to correlations between competitive culture and the dimension of organisational learning at team level $(r=0.268, p<0.01)$ as well as the correlations between competitive culture and the dimension of learning at organisational level $(r=0.242, p<0.01)$. The coefficient between competitive culture and the dimension of organisational learning at individual level produces the highest result followed by learning at team level. The correlation coefficient between entrepreneurship culture and learning at individual level $(r=0.493, p<0.01)$ also suggests a positive and significant relationship. The relationship between entrepreneurship culture and dimension of organisational learning at team level $(r=0.409, p<0.01)$, while with that of learning at organisational level $(r=0.360, p<0.01)$ was also significant. The correlation coefficient between bureaucratic culture and the dimension of learning at individual, team and organisational levels $(r=0.392,0.388$ and 0.330 respectively, they are all significant at $p<0.01$ ). This demonstrates that there is a positive and significant relationship between bureaucratic culture and human resource development policy at all levels in the Nigerian banking sector. The correlation coefficients between consensual culture and the dimension of learning at individual, team and organisational levels $(r=0.652,0.503$ and 0.516 respectively, they are all significant at $p<0.01)$. This implies that there is a significant strong but positive relationship between consensual culture and human resource development policy in the Nigerian banking sector. The interplay between overall organisational culture and human resource development policy in the Nigerian banking sector can be found in table 3 .

Tables 3: Pearson ccorrelation between organisational culture and human resource development policy

\begin{tabular}{|l|c|c|c|c|c|}
\hline & N & Mean & Std. D & R & P \\
\hline Organisational culture & 305 & 52.3475 & 6.53059 & \multirow{2}{*}{$.576^{* *}$} & \multirow{2}{*}{0.00} \\
HR development policy & 305 & 47.8361 & 7.38504 & & \\
\hline
\end{tabular}

**. Correlation is significant at $p<0.01$ level (2-tailed).

Table 3 shows the correlation between organisational culture and the HR development policy is . 576 , this is significant at 0.01 level $(r=.576, p<0.01)$. This suggests that there is significant positive relationship between organisational culture and HR development policy in the Nigerian banking sector. The value of $p$ which is 0.00 is lower than 0.01 and the correlation coefficient of 0.576 or $57.6 \%$. With this level of significant, the null hypothesis is hereby rejected, which led to the acceptance of the alternative hypothesis stating; that there is a significant relationship between organisational culture and HR development policy in the Nigerian banking sector. However, the relationship between the two variables is not only significant; it is equally strong and positive. Table 4 presents the result of multiple regressions based on the significance level of different cultural dimensions as predictors of HR development policy as an antecedent of HR/organisational outcomes in the Nigerian baking sector.

\subsection{Relationship between the cultural dimensions and HR development policy}

Table 4: Regression analysis between the cultural dimensions and HR development policy

\begin{tabular}{|l|c|c|c|c|c|c|c|}
\hline \multicolumn{1}{|c|}{ Independent variable } & $\mathrm{R}$ & $\mathrm{R}$ square & Adjusted R square & $\mathrm{F}$ & Beta & $\mathrm{T}$ & $\mathrm{P}$ \\
\hline & $.657^{\mathrm{a}}$ & .432 & .424 & 56.936 & - & - & $.000^{\mathrm{b}}$ \\
\hline Competitive culture & & & & & -.073 & -1.261 & .208 \\
\hline Entrepreneurship culture & & & & & .179 & 2.919 & .004 \\
\hline Bureaucratic culture & & & & & .100 & 1.773 & .077 \\
\hline Consensual culture & & & & & .518 & 9.398 & .000 \\
\hline Constant & & & & - & 5.359 & .000 \\
\hline
\end{tabular}

The regression model in table 4 reveals $\mathrm{R}$ square of .432 and adjusted $\mathrm{R}$ square of .424 . This means that the model (cultural dimensions) predicts $42.4 \%$ of the variations in HR development policy in the Nigerian banking sector. This is significant at $(p<0.01)$ meaning that there is a significant relationship between the independent variables of different dimensions of organisational culture and the dependent variable (HR development policy). These results support the alternative hypothesis stating that there is a significant relationship between organisational culture and HR development policy. The standardised Beta and the corresponding $P$ values for consensual and entrepreneurial culture $(\beta=.518, p<$ 
$0.01)$ and $(\beta=.179, p<0.01)$ respectively, show that consensual culture made the largest contributions to the model, followed by the entrepreneurial culture. With these results, one can conclude that consensual and entrepreneurial cultures jointly serve as a predictor of HR development policy in the Nigerian banking sector. Interestingly, this result is similar to the research outcomes conducted by Ezirim et al. (2010a), the only exception was that competitive culture also made a unique contribution in relation to performance in the study.

\section{Conclusion and Recommendations}

The overall objective of this study was to investigate the relationship between organisational culture and human resource development policy as an antecedent of HR/organisational outcomes. Our findings suggest that a well communicated corporate culture through HR development policy provides explicit guidelines for shaping employee attitudes and behaviours in order to address the variations in the knowledge-based global economy. This was ascertained with the level of significance in the relationship between organisational culture and human resource development policy in the Nigerian banking sector. The relationship is not only positive but also suggests strong association between the two variables. The specific objective was also realised as evident in the standardised beta and the corresponding level of significance for consensual culture as a dimension of organisational culture. This implies that consensual culture made the greatest contributions to human resource development policy in the regression model investigated. While the entrepreneurship culture on the other hand, also made significant contribution in the model. On the contrary, the contributions competitive and bureaucratic cultures in the Nigerian banking sector are insignificant based on the outcomes of this study. Hence, the two hypotheses formulated and tested in this study were empirically supported. We found that organisational culture and human resource development policy were significantly correlated. However, consensual and entrepreneurship cultures made unique contributions in the regression model as provided in table 4. This result is not surprising, since it corroborated the empirical studies conducted by Desphande and Farley (1999) as well as Ezirim et al (2010). The only exception was that competitive culture also made significant contributions to dependent variables in the previous studies. Conclusively, this paper has been able to provide statistical evidence that there is a positive relationship between organisational culture and human resource development policy as an antecedent of human resource/organisational outcomes in the Nigerian banking sector.

The management implications emanated from the findings are that the relationship between organisational culture and HR development policy are an antecedent of employee skills, attitudes and work behaviours. From the findings, we learn that organisational culture should be explicitly communicated through HR development policy such as; coaching, mentoring, orientation or induction course and other job cited management training schemes. This will have a positive impact on employee skills, attitudes and behaviours leading to organisational efficiency. Another implication for the management is that consensual and entrepreneurship culture should be properly communicated through learning and development policy. This implies that consensual and entrepreneurial cultures are crucial for business sustainability in the knowledge-based global economy. Creativity and innovations in the global economy requires effective utilisation of entrepreneurship culture via knowledge creation.

\section{Limitation and Future Research}

The scope of this study is limited to the Nigerian banking sector focusing on the relationship between organisational culture and human resource development policy. Hence, this paper focused on measuring learning and development policy as an antecedent of human resource/organisational outcomes. Therefore, there is a need to explain the relationship between organisational culture and performance using human resource development policy as a mediating variable. This could be analysed or better explained via Structural Equation Modelling (SEM). Future research should consider this as a wake up call in order to fill the gap by providing the causal path on the link between organisational culture and performance in different sectors of the economy.

\section{Acknowledgement}

This paper is based on a PhD study at the University of KwaZulu-Natal, Prof. Chitakunye and Dr Fields are the supervisors of the study. 


\section{References}

Aggarwal, U., \& Bhargava, S. (2009). Reviewing the relationship between human resource practices and psychological contract and their impact on employee attitude and behaviours: A conceptual model. Journal of European Industrial Training, 33(1), 4-31.

Banabou, C. (1996). Assessing the impact of training programmes on the bottom-line. National Productivity Review, 15(3), 92-99.

Cheung, S. O., Wong, P. S. P., \& Lam, A. L. (2012). An investigation of the relationship between organizational culture and the performance of construction organizations. Journal of Business Economics \& Management, 13(4), 688-704. doi: 10.3846/16111699.2011.620157

Clarke, N. (2004). Human resource development and the challenges of assessing learning in the workplace. International Journal of Training and Development, 8(2), 140-156

Debowski, S. (2006). Knowledge management. Australia: John Wiley \& Sons Australia, Ltd.

Denison, D. R., Haaland, S., \& Goelzer, P. (2004). Corporate culture and organisational effectiveness: Is Asia different from the rest of the world? Organisational Dynamics 33(1), 98-109.

Deshpande, R., \& Farley, J. U. (1999). Corporate culture and market orientation: Comparing Indian and Japanese firms. Journal of International Marketing, 111-127.

Deshpandé, R., \& Farley, J. U. (2004). Organizational culture, market orientation, innovativeness, and firm performance: an international research odyssey. International Journal of Research in Marketing, 21(1), 3-22. doi: http://dx.doi.org/10.1016 j.jjresmar. 2003.04.002

Dimovski, V. (1994). Organizational learning and competitive advantage. (Ph.D), Cleveland.

Egan, T. M., Yang, B., \& Bartlett, K. R. (2004). The effects of organizational learning culture and job satisfaction on motivation to transfer learning and turnover intention. Human resource development quarterly, 15(3), 279-301.

Ellinger, A. D., Ellinger, A. E., Yang, B., \& Howton, S. W. (2002). The relationship between the learning organization concept and firms' financial performance: An empirical assessment. Human resource development quarterly, 13(1), 5-22.

Engelen, A. (2010). Entrepreneurial orientation as a function of national cultural variations in two countries. Journal of International Management, 16(4), 354-368.

Ezirim, C. B., Nwibere, B. M., \& Emecheta, B. C. (2010a). Organisational culture and performance: The Nigerian experience. International Journal of Business \& Public Administration, 7(1), 40-56.

Ezirim, C. B., Nwibere, B. M., \& Emecheta, B. C. (2010b). Organisational culture and performance: the nigerian experience. International Journal of Business \& Public Administration, 7(1), 40-56.

Ezirim, C. B., Nwibere, B. M., \& Emecheta, B. C. (2012). The influence of corporate culture on organisational commitment: The Nigerian experience International Journal of Business \& Public Administration, 9(3), 155-180.

Gambi, L. d. N., Gerolamo, M. C., \& Carpinetti, L. C. R. (2013). A theoretical model of the relationship between organizational culture and quality management techniques. Procedia - Social and Behavioral Sciences, 81(0), 334-339. doi: http://dx.doi.org/10.1016 j.sbspro.2013.06.438

Garavan, T. N., \& Morley, M. J. (2006). Re-dimensionalsing boundaries in the theory and practice of human resource development. Learn Intellect Capital, 3(1), 3-13.

Garvin, D. A. (1993). Building a learning organization. Harvard Business Review 71, 78-91.

Goh, S. C. (1998). Toward a learning organisation: The strategic building blocks. Advanced Management Journal, 63(2), 15-20.

Gregory, B. T., Harris, S. G., Armenakis, A. A., \& Shook, C. L. (2009). Organisational culture and effectiveness: A study of values, attitudes, and organizational outcomes. Journal of Business Research, 62(7), 673-679. doi: http://dx.doi.org/10.1016 jj.jbusres.2008.05.021

Hartnell, C. A., Ou, A. Y., \& Kinicki, A. (2011). Organisational culture and organizational effectiveness: a meta-analytic investigation of the competing values framework's theoretical suppositions. Journal of Applied Psychology, 96(4), 677.

Hedt, B. L., \& Pagano, M. (2011). Health indicators: eliminating bias from convenience sampling estimators. Statistics in Medicine, 30(5), 560-568.

Huang, S. K., \& Wang, Y.-L. (2011). Entrepreneurial orientation, learning orientation, and innovation in small and medium enterprises. Procedia-Social and Behavioral Sciences, 24, 563-570.

Hung, R. Y. Y., Yang, B., Lien, B. Y.-H., McLean, G. N., \& Kuo, Y.-M. (2010). Dynamic capability: Impact of process alignment and organizational learning culture on performance. Journal of World Business, 45(3), 285-294. doi: http://dx.doi.org/10.1016/ j.jwb.2009.09.003

Javidan, M., House, R. J., Dorfman, P. W., Hanges, P. J., \& Luque, M. S. (2006). Conceptualizing and measuring cultures and their consequences: A comparative review of GLOBE's and Hofstede's approaches. Journal of International Business Studies 37(6), 897-914.

Kehinde, J. S., Jegede, C. A., Akinlabi, H. B., \& ce. (2012). Impact of leadership skill and strategies on banking sector performance: A survey of selected consolidated banks in Nigeria. Paper presented at the International Trade \& Academic Research Conferen, London, UK.

Kotter, J. P., \& Heskett, J. L. (1992). Corporate culture and performance. New York: : The Free Press.

Latif, K. F. (2012). An integrated model of training effectiveness and satisfaction with employee development interventions. Industrial and Commercial Training, , 44(4), 211-222.

Liao, S.-H., Chang, W.-J., Hu, D.-C., \& Yueh, Y.-L. (2012). Relationships among organisational culture, knowledge acquisition, 
organizational learning, and organizational innovation in Taiwan's banking and insurance industries. The International Journal of Human Resource Management, 23(1), 52-70.

Mathew, J., Ogbonna, E., \& Harris, L. C. (2012). Culture, employee work outcomes and performance: An empirical analysis of Indian software firms. Journal of World Business, 47(2), 194-203. doi: http://dx.doi.org/10.1016/j.jwb.2011.04.006

Mello, J. A. (2011). Strategic management of human resources (3rd ed.). Canada: Nelson Education Ltd.

Metcalfe, B. D. (2011). Women, empowerment and development in Arab Gulf States: a critical appraisal of governance, culture and national human resource development (HRD) frameworks. Human Resource Development International, 14(2), 131-148.

Mondy, R. W. (2010). Human resource management (11th ed. ed.). Upper Saddle River, New Jersey: Pearson/Prentice Hall.

Murray, P., \& Donegan, K. (2003). Empirical linkages between firm competencies and organisational learning. The Learning Organization, 10, 51-62.

Nadarajah, S., Kadiresan, V., Kumar, R., Kamild, N. N. A., \& Yusoff, Y. M. (2012). The relationship of human resource practices and job performance of academicians towards career development in malaysian private higher institutions. Procedia - Social and Behavioral Sciences, 57, $102-118$

Naranjo-Valencia, J. C., Jiménez-Jiménez, D., \& Sanz-Valle, R. (2011). Innovation or imitation? The role of organizational culture. Management Decision, 49(1), 55-72.

Prajogo, D., Chowdhury, M., Yeung, A. C. L., \& Cheng, T. C. E. (2012). The relationship between supplier management and firm's operational performance: A multi-dimensional perspective. International Journal of Production Economics, 136(1), 123-130. doi: http://dx.doi.org/10.1016/j.ijpe.2011.09.022

Prajogo, D. I., \& McDermott, C. M. (2011). The relationship between multidimensional organizational culture and performance. International Journal of Operations \& Production Management, 31(7), 712-735.

Rashid, Z. A., Sambasivan, M., \& Johari, J. (2003). The influence of corporate culture and organisational commitment on performance. Journal of Management Development, 22(8), 708-728.

Reynolds, J. (2004). Helping people learn. London: Chartered Institute of Personnel Development.

Schneider, B., Ehrhart, M. G., \& Macey, W. H. (2013). Organizational climate and culture. Annual review of psychology, 64, $361-388$.

Singh, H., Motwanis, J., \& Komar, A. (2000). A review and analysis of the state-of-the-art research on productivity measurement. Industrial Management \& Data Systems, 100(5), 234-241.

Škerlavaj, M., Štemberger, M. I., Škrinjar, R., \& Dimovski, V. (2007). Organizational learning culture-the missing link between business process change and organizational performance. International Journal of Production Economics, 106(2), 346-367. doi: http://dx.doi.org/10.1016/j.jpe.2006.07.009

Song, J. H., Chermack, T. J., \& Kim, W. (2013). An analysis and synthesis of DLOQ-based learning organisation research. Advances in Developing Human Resources, 15(2), 222-239.

Stavrou, E. T., Charalambous, C., \& Spiliotis, S. (2007). Human resource management and performance: A neural network analysis. European Journal of Operational Research, 181(1), 453-467.

Thang, N., Quang, T., \& Buyens, D. (2010). The relationship between training and firm performance: A literature review. Research and practice in human resource management, 18(1), 28-45.

Thite, M. (2011). Smart cities: implications of urban planning for human resource development. Human Resource Development International, 14(5), 623-631.

Wang, X., Yang, B., \& McLean, G. N. (2007). Influence of demographic factors and ownership type upon organisational learning culture in Chinese enterprises. International Journal of Training and Development, 11(3), 154-165.

Watkins, K. E., \& Marsick, V. J. (2003). Making learning count! Diagnosing the learning culture in organisations. Califonia: Sage publication.

Werner, J. M., \& DeSimone, R. L. (2009). Human resource development, . USA: South-Western Centage Learning.

Wilkens, U., Menzel, D., \& Pawlowsky, P. (2004). Inside the Black-box: Analysing the Generation of Core Competencies and Dynamic Capabilities by Exploring Collective Minds. An Oganisational Learning Perspective. management revue. The International Review of Management Studies, 15(1), 8-26.

Yang, B. (2003). Identifying valid and reliable measures for dimensions of a learning culture. Advances in Developing Human Resources, 5(2), 152-162. 